\title{
DOCUMENTO
}

\section{CONSIDERAÇÕES DA ASSOCIAÇÃO BRASILEIRA DE ENFERMAGEM SOBRE A PROPOSTA DE REFORMULAÇÃO DO CURRÍCULO MÍNIMO PARA A FORMAÇÃO DO ENFERMEIRO*}

\author{
Maria Auxiliadora Córdova Christófaro**
}

\begin{abstract}
Os fundamentos científicos, os processos, os procedimentos, os métodos, as metodologias e as técnicas inerentes ao exercício do cuidar de pessoas (como individuos e grupos - sadios, doentes e expostos a riscos de adoecer e morrer) constituem o eixo nuclear do saber do enfermeiro. A ampliação do conhecimento, em especial das ciências biológicas e humanas, paralela à complexificação e tecnificação da sociedade tornou "o cuidar de pessoas" um processo cada vez mais diversificado, complexo, institucionalizado, com múltiplas interfaces e demandas. A sociedade contemporânea trouxe a todas as áreas de conhecimento e de trabalho humanos uma exigência fundamental: acompanhar, incorporar e participar deste processo. A área e/ou grupo social que venha "abrir mão" de estar efetivamente nesta dinâmica tenderá a perder sua legitimidade e identidade social. Para a área de saúde em geral e para a enfermagem em particular, tornou-se essencial a redefinição dos paradigmas que as sustentam e conformam. $\mathrm{O}$ "pensarfazer-saber" de cada um dos profissionais que compartem o exercício de cuidar de pessoas vem passando por rápidas e freqüentes redefinições, o que tem gerado:
\end{abstract}

novas formas, modos e métodos de gestão do trabalho em saúde;

múltiplas e diferentes metodologias, procedimentos e recursos propedêuticos e terapêuticos;
- maior abrangência dos métodos e conteúdos teórico-práticos que conformam o exercício de cada profissão específica, entre outras.

Tal processo justifica, explica e demanda que setores, instituições, organismos (sociais, políticos e científicos), busquem reorientar sua prática e expressem isto nos regulamentos e regulações que os conformam.

Na enfermagem estas redefinições têm transformado significativamente a "praxis" profissional. De uma atuação quase doméstica, limitada e restrita ao "corpo doente", hoje é exigido do(a) enfermeiro (a) uma interação cada. vez mais sistematizada, ampla e científica com os processos individuais e coletivos de saúde-doença, assim como com o processo de produção de serviços de saúde, de formação de profissionais e de investigação. Extrapolar o "ethos" biológico, normativo e prescritivo é um dos desafios da enfermagem hoje. $\mathrm{O}$ trabalho da enfermagem como um todo e da enfermeira, circunscrito aos cuidados ao "corpo doente " hegemônico por muitas décadas, exigia única e exclusivamente que seus exercentes fossem "donos" de extrema dedicação, generosidade, caridade e capacidade de obediência. Sem negar o significado e importância desses valores para o exercício de cuidar de pessoas, hoje exige-se que a enfermagem tenha requisitos, instrumentos, meios e qualificações para além destas virtudes e dons.

\footnotetext{
* Documento encaminhado ao Conselho Federal de Educação, em novembro/1993, como anexo a ofício da ABEn ao relator do processo de reformulação curricular, em tramitação no CFE desde setembro/91.

** Prof essora Assistente do Departamento de Enfermagem Materno-Infantil e Saúde Pública da UFMG. Presidente da Associação Brasileira de Enfermagem.
} 
A institucionalização e predominância da assistência à saúde através dos hospitais. os resultados e demandas das ciências e da complexa organização social demonstram que o cuidado doméstico, fundamentado no bom senso e o hospital como mero repetidor de atos domésticos, não respondem cfetivamente às necessidades e demandas de saúde das populações e do indivíduo. e não mais correspondem ao estágio de desenvolvimento tecnológico da sociedade moderna. A enfermagem "caminhou" da casa para o hospital, e deste para diversos setores e áreas da sociedade, ampliando e complexificando suas ações e conhecimentos. Exercida, atualmentc. por três categorias profissionais - enfermeiro, técnico e auxiliar de enfermagem - realiza ações diferenciadas, interdependentes, colaborativas e articuladas com o trabalho de diferentes outros profissionais, em diferentes instituições de saúde. inclusive, como prática autônoma e liberal. Torna-se assim imprescindível o estabelecimento de estratégias que dêem conta de manter a atualização da enfermagem e sua pertinência c aderência técnica, científica, social e ética com este momento. Neste sentido, a formação do enfermeiro. deve permitir-lhe tomar parte do processo de atenção à saúde, seja em atividades assistenciais, administrativas, educativas e de investigação, tanto no setor hospitalar como no não hospitalar. devendo diversificar sua inserção para outros setores que não o específico de saúde, como por exemplo o setor de educação, onde "tem lugar" a formação dos profissionais de nível médio que compõem a enfermagem.

Atendendo a esta multiplicidade de exigências e em consonância com a ampliação dos conhecimentos advindos das ciências humanas, físicas e biológicas, somados às injunções da organização político-social da sociedade, o enfermeiro se coloca, cada vez mais, como um profissional estratégico e essencial à produção de serviços na e para a área de saúde. Ao desafio de tornar-se competente na coordenação, planejamento e execução do trabalho da enfermagem como um todo, articulando-o com o trabalho dos demais profissionais de saúde, o enfermeiro, no Brasil, deverá capacitar-se para intervir na profissionalização de um gnupo quantitativamente significativo na área da saúde: aquele formado por pessoas sem qualificação para o trabalho de enfermagem e que vem sendo absorvido ao longo da história do País, graças às políticas sociais compensatórias que foram e são privilegiadas em detrimento de princípios mínimos da ética, da justiça e da qualidade dos serviços de saúde. A este desafio estrutural e contextual somam-se outros, tais como: a experimentação e a criação de novos meios, instrumentos de trabalho. modelos, padrões e parâmetros tecnológicos. adequados e pertinentes à assistência de saúde individual e coletiva. Tais demandas e desafios, juntos, justificam repensar e rever os eixos básicos da formação do enfermeiro garantindo no nível da graduação, os aportes técnico-científicos-sociais que preparem e capacitem o enfermeiro para realizar e/ou co-participar:

- dos processos propedêuticos, terapêuticos e educativos de promoção, de proteção, de cura e de recuperação da saúde de indivíduos e grupos;

- da organização, planejamento, programação e avaliação do trabalho da enfermagem;

- da formação de profissionais de enfermagem de nível médio:

- da investigação enquanto criação, implantação, execução e avaliação de metodologias, procedimentos e técnicas propedêuticas e terapêuticas apropriadas e concernentes às necessidades de saúde.

Logicamente a reformulação de um diploma jurídico, como o é um currículo mínimo, não será causa exclusiva c única que sustentará e assegurará a reorientação da profissão. Se por um lado tal assertiva é óbvia, por outro, é verdade que, se as normas que regulam determinado processo estão defasadas em relação à realidade, ocorre uma flagrante redução do "movimento" da profissão e dos profissionais. Tal situação transf orma a reformulação das normas numa questão essencial e prioritária, porque amplia as possibilidades de concretização das mudanças pretendidas. O Parecer CFE 163/72 e a Resolução CFE 04/72 que regulamentam a formação do enfermeiro ainda hoje, não se justificȧm mais. $\mathrm{O}$ processo de transição demográfico-epidemiológica porque passa a sociedade brasileira, a incorporação e utilização de tecnologias pelo setor saúde, somadas à ampliação do conhecimento clínico-epidemiológico. e as propostas de reorganização do sistema ade saúde não permitem que o parâmetro legal. que normatiza o patamar mínimo da formação do enfermeiro (o currículo mínimo) permaneça como expressão do que se vivia há mais de vinte anos, tanto na enfermagem, como na saúde, na ciência médica e no contexto social. Foi, sem dúvida, esta constatação e análise que motivaram as Escolas e Faculdades de Enfermagem, a Associação Brasileira de Enfermagem (ABEn Nacional) e a Comissão de Especialistas em Enfermagem da Secretaria de Ensino Superior do Ministério de Educação (CEEn/SENESU-MEC) a promoverem estudos sobre a matéria. Tais estudos congregaram toda a comunidade de enfermagem em torno da avaliação analítica 
e crítica das normas que definem os mínimos de conteúdo e duração do curso de graduação em enfermagem, hoje. Destes processos foi sendo consolidada a proposta de reformulação do currículo mínimo, que ora se submete ao Egrégio Conselho Federal de Educação. Ressalta-se, que por solicitação da ABEn, a referida proposta passou por avaliação da SENESU que, através de parecer assinado pela Professora Doutora Maria Cecília Puntel de Almcida (Escola de Enfermagem da USP-Ribeirão Preto), manif cstou-sc favoravelmente à proposta como formulada pela comunidade da enfermagem.

\section{HISTÓRICO E SITUAÇÃO}

O processo que culminou com a claboração da proposta foi sistematicamente programado e executado. Contou com a participação das escolas de todas as regiões do país (professores, alunos, ex-alunos e enfermeiros dos serviço de saúlde); com as entidades de enfermagem (ABEn, Federação e Sindicatos) e com os Conselhos Federal/Regional de Enfermagem. Formalmente, iniciou com 4 (quatro) seminários (Região Norte/Nordeste; Região Sul: Região CentroOeste e Região Sudeste) objetivando ' carcicterizar a situação do ensino de graduação em enfermagem por região e apresentar alternativas para os problemas identificados ". Tais seminários ocorreram no período de setembro/86 a setembro/87 e seus resultados foram consolidados e analisados em um Seminário Nacional em outubro/87, no Rio de Janeiro. Desta etapa resultaram pontos comuns e postulados gerais, que subsidiaram o trabalho posterior $\mathrm{e}$ foram contemplados na proposta de formação do enfermeiro que tramita no CFE. Neste mesmo período e até outubro/88, teve início uma segunda etapa que diferentemente da anterior realizou primeiramente um seminário nacional sobre 'perfil e competência do enfermeiro', seguido de 4 (quatro) outros seminários regionais sobre os mesmos aspectos. A esta atividade seguiu uma oficina de trabalho com representantes regionais, objetivando uma articulação entre as atividades anteriores. Nesta oficina foi reelaborado o cronograma do trabalho, buscando assegurar os espaços e o tempo necessários à formulação final da proposta. A partir da proposta preliminar resultante dos estudos anteriores, e com base nos problemas e demandas identificados, nos postulados e princípios estabelecidos como fundamentais, realizou-se um encontro nacional em Niterói, onde foi aprovada uma proposta formal de reformulação do atual currículo mínimo. De posse desta proposta, a $\mathrm{ABEn}$ procedeu à sua divulgação, objetivando a análise pela comunidade de enfermagem. Em $1989\left(41^{\circ}\right.$ Congresso Brasilciro de Enfermagcm cm Florianópolis - SC) c em 1990 (42 ${ }^{\circ}$ Congresso Brasilciro de Enfermagem em Natal - RN), a proposta divulgada nacionalmente, foi rediscutida $\mathrm{C}$ complementada, sendo aprovada a sua formulação final c o seu encaminhamento ao Ministério da Educação/Conselho Federal de Educação. A Comissõa responsável pela formulação final do documento, apresentou-o em oficina de trabalho em maio/91 e uma última revisão foi feita. A proposta foi então encaminhada à SENESU (onde recebeu parecer favorável em março/92 - Parecer da Profa. Doutora Maria Cecília Puntcl de Almeida - USP/Ribeirão Preto) e ao Conselho Federal de Educação. A proposta tem o apoio de todas as Escolas e Entidades de Enfermagem e todas reivindicam, insistentemente, sua aprovação.

\section{JUSTIFICATIVA}

A presente proposta tem como justificativa, entre outras:

1. a constatação unânime da enfermagem, de que a legislação $\mathrm{cm}$ vigor desde 1972, não permite adequar o processo de formação do enfermeiro às transformações da profissão, da área de saúde, do ensino, do mercado de trabalho e, principalmentc às necessidades e damandas de saúde da população, expressas pela significante mudança no perfil demográfico-epidemiológico do País;

2. a flagrante compartimentalização e minimização do conhecimento, estabelecido na legislação em vigor, resulta em um processo de formação anacrônico onde o enfermciro 'aparece' em falsas e frágeis vertentes: habilitação geral e habilitações específicas. Sobre cste aspecto, o que as atuais normas produzem, de fato, é a indefinição do profissional. As chamadas habilitações específicas (por áreas) cujo oferecimento é opcional para a Instituição e para os alunos, tornaram a formação do enfermeiro em um processo pulverizado em detrimento de um processo que privilegie as bases técnicas-científicas da profissão;

3. o privilegiamento do modelo individual e biomédico de assistência centrado fundamentalmente no hospital, claramente expresso nas atuais normas (o conteúdo de saúde pública na habilitação geral do enfermeiro está reduzida à introdução a saúde pública). 
Embasada nestes pontos consensuais, a enfermagem brasileira delineou uma proposta cujos Pressupostos, Diretrizes e Principios, são:

a. o currículo mínimo do curso de graduação em enfermagem deve ser considerado como referência nacional e tem como terminalidade a formação do enfermeiro;

b. a essencialidade e a "vocação "de cada instituição formadora devem estar expressas na formulação de cada currículo pleno, onde deve ser assegurada a mais estreita relação com: os problemas e as necessidades de saúde da região onde se localiza a instituição formadora e os parâmetros estabelecidos na Constituição Federal e na Lei Orgânica de Saúde para o SUS;

c. a ampliação e a permanente atualização do processo de formação devem ser garantidas através da flexibilidade curricular, integração ensino/serviço; criação/manutenção/consolidação de grupos de pesquisa; recursos bibliográficos e didáticos apropriados e atualizados; qualificação do corpo docente; intercâmbio interinstitucionais;

d. as matérias que compõem um currículo mínimo devem indicar as áreas do conhecimento, geral e específico, que sustentam a preparação do enfermeiro, devendo o seu desdobramento, em disciplinas, ser objeto de definição de cada escola, assegurando a qualificação clínico, epidemiológica, técnica e ética do profissional, de forma a permitir-lhe o exercício da profissão, tanto na área assistencial (propedêutica e terapêutica) como nas áreas de administração, educação e de investigação;

e. a competência técnico-científica e política a ser adquirida, no nível de graduação, deve conferir ao enfermeiro capacidade profissional para a inserção no mercado de trabalho, considerando as demandas e necessidades de saúde prevalentes e prioritárias da população, conforme o quadro epidemiológico do país/região;

f. o aprof undamento da qualificação técnico-científica do enfermeiro deve ser objeto de estudos posteriores, através das especializações, no nível de pós-graduação "lato sensu" e "stricto sensu" extinguíndo-se as habilitações no nível de graduação;

g. a formação do enfermeiro deve contemplar atividades e conteúdos teóricos e práticos incluindo, nestes últimos, o estágio curricular, sob supervi- são. Isto significa que além das atividades teóricas (aulas, seminários e outros estudos da mesma natureza) o currículo contemplará: o ensino prático comumente adotado pelas escolas (laboratórios, ensino-clínico nas diversas áreas da assistência e dos serviços de saúde hospitalares e de rede básica) $\mathrm{e}$, pelo menos um semestre letivo, de estágio curricular supervisionado, a ser programado, acompanhado e avaliado pela escola e pelos enfermeiros dos serviços de saúde onde se realizarão tais estágios. As atividades práticas (ensino clínico e estágio) terão como "locus "as unidades de serviços com internação (hospitais) e sem internação (rede básica de serviços e ambulatórios).

Isto posto, são essenciais na proposta, as seguintes reformulações:

1. aumentar a duração minima do curso - o mínimo de 4 (quatro) anos (8 semestres letivos) e o máximo de 5 (cinco) anos (10 semestres);

2. aumentar o número mínimo de horas - mínimo 3.500 (três mil e quinhentas) horas;

3. suprimir as diferentes habilitações no nivel da graduação;

4. incluir conteúdos didáticos-pedagógicos, o que instrumentalizará todos enfermeiros para desenvolver atividades docente, nos cursos de nível médio que formam auxiliar e o técnico de enfermagem;

5. manter os contevidos das ciências biológicas $e$ humanas, não como estão hoje - "noções de" mas como conteúdos substantivos concernentes ao trabalho do enfermeiro, incluindo na área de ciências humanas além de Sociologia e Psicologia, a Filosofia;

6. incluir conteúdos instrumentais básicos para a capacitação clinico-epidemiológica (assistencial), administrativa e pedagógica do en fermeiro, como: estatística, epidemiologia, semiologia e semiotécnica da enfermagem, vigilância à saúde e ambiente;

7. definir, como minimo, os conteúdos de matérias e disciplinas que contemplem:

- a assistência de enfermagem à criança, adolescente, adulto (incluindo a especificidade da mulher e do adulto na terceira idade) em situações Clínicas, Cinúrgicas, Gineco-Obstétricas e Psiquiátricas, tanto no nível da assistência individual como 
de saúde pública. em serviços não hospitalares (ambulatórios/rede básica) e $\mathrm{cm}$ hospitais;

administração e gerência de serviços de saúde (unidades locais de saúde e hospitais de médio porte) e de enfermagem;

8. incluir conteúdos da história da enfermagem, ética, leis e regulações do exercício da enfermagem;

9. incluir estágio supervisionado e curricular com duração mínima de 1 (um) semestre letivo, em hospitais e rede básica de serviços de saúde.

\section{CONCLUSÃO}

A enfermagem brasileira realizou um trabalho amplo de estudo e análise das atuais normas que regulam a formação do enfermeiro, que pode ser caracterizado como um processo político e pedagógico de relevância. A demanda que a enfermagem tem hoje é reformular as bases legais que regem a formação do enfermeiro. Tais estudos demonstram que a posição da enfermagem, exigindo esta reformulação, é estratégica e essencial como parte da reorientação da "praxis" do enfermeiro e do seu papel técnico-social. 